\title{
A Assistência Social como Política Pública
}

\author{
La Asistencia Social como una Política Pública
}

Social Assistance as a Public Policy

\author{
Daniele Bonapace dos Santos Lencina ${ }^{1}$
}

\begin{abstract}
Resumo
A Política Pública de Assistência Social, a partir da Constituição Federal de 1988, busca construir uma trajetória diferente das antigas propostas assistencialistas, que serviam de alicerce para as políticas construídas até então, de forma a possibilitar o acesso aos serviços assistenciais através de uma proposta de direito social. O presente artigo aborda a relação que há entre o antigo assistencialismo e a atual Política Pública de Assistência Social, buscando avaliar seus avanços e desafios, bem como os limites de acesso dos usuários que necessitam dela, objetivando encontrar meios para minimizar a pobreza e a desigualdade. Analisaram-se criticamente os atuais métodos de avaliação das Políticas Públicas no Brasil, suas limitações, perspectivas e necessidades futuras. Observou-se que houve um grande avanço no tocante ao reconhecimento da Assistência Social como Política Pública, porém a efetivação na prática desta Política no âmbito do direito social ainda se constitui um grande desafio. O Estado, na gestão de uma Política Pública de Assistência Social, não pode permanecer no papel de coadjuvante que concede ajudas financeiras, subsídios a ações, trabalhos ou projetos comunitários. Portanto, é preciso que alcance e assuma o papel de regulador e responsável por garantir proteção social como política de cidadania, isto é, nem compensatória, nem caridosa, nem assistencialista, mas sim como uma Política Pública de direitos. A transição da Assistência Social para o âmbito da Política Pública exige que ela vá além de uma identificação de programa social deste ou daquele governo para desenvolver um sistema de proteção social efetivo e contínuo.
\end{abstract}

Palavras-Chave: Políticas Públicas. Assistência Social. Assistencialismo. Estado.

\section{Resumen}

La Política Pública de Asistencia Social, basada en la Constitución Federal de 1988, busca construir una trayectoria diferente a las antiguas propuestas de bienestar, que sirvieron de base a las políticas construidas hasta entonces, para permitir el acceso a los servicios de salud a través de una propuesta de la ley social. Este artículo discute la relación entre el anterior estado de bienestar y la actual Política de Asistencia Social Pública, buscando evaluar sus avances y desafíos, así como los límites de acceso de los usuarios que lo necesitan, con el objetivo de encontrar medios para minimizar la pobreza y la desigualdad. Los métodos actuales de evaluación de Políticas Públicas en Brasil, sus limitaciones, perspectivas y necesidades futuras fueron analizados críticamente. Se observó que hubo un gran avance en el reconocimiento de la Asistencia Social como Política Pública, pero la implementación efectiva de esta Política en el ámbito de las leyes sociales sigue siendo un gran desafío. El Estado, en la gestión de una Política Pública de Asistencia Social, no puede permanecer en el rol de auxiliar que otorga ayuda financiera, subsidios a acciones, obras o proyectos comunitarios. Por lo tanto, debe alcanzar y asumir el rol de regulador y responsable de garantizar la protección social como una política de ciudadanía, es decir, no compensatoria ni caritativa ni asistencialista, sino como una Política Pública de derechos. La transición de la Asistencia Social al ámbito de las Políticas Públicas requiere que vaya más allá de la identificación de un programa social de este o aquel gobierno para desarrollar un sistema de protección social efectiva y continua.

Palabras-clave: Políticas Públicas. Asistencia Social. Bienestar. Estado.

\footnotetext{
1 Bacharel em Direito; Especialista em Direito do Trabalho; Faculdade São Braz; Rio Grande do Sul; danielebonapace@hotmail.com;
} 


\begin{abstract}
The Public Policy of Social Assistance, based on the Federal Constitution of 1988, seeks to build a different trajectory from the old welfare proposals, which served as a foundation for the policies built until then, in order to enable access to health services through a proposal of social law. This article discusses the relationship between the former welfare state and the current Public Social Assistance Policy, seeking to evaluate its advances and challenges, as well as the access limits of users who need it, with the aim of finding means to minimize poverty and inequality. The current methods of evaluating Public Policies in Brazil, their limitations, perspectives and future needs were critically analyzed. It was observed that there was a great advance in the recognition of Social Assistance as Public Policy, but the effective implementation of this Policy in the scope of social law is still a great challenge. The State, in the management of a Public Policy of Social Assistance, cannot remain in the role of auxiliary that grants financial aid, subsidies to actions, works or community projects. Therefore, it must reach and assume the role of regulator and responsible for guaranteeing social protection as a citizenship policy, that is, neither compensatory nor charitable nor assistentialist, but as a Public Policy of rights. The transition from Social Assistance to the scope of Public Policy requires that it go beyond identifying a social program of this or that government to develop a system of effective and continuous social protection.
\end{abstract}

Keywords: Public Policie. Social Assistance. Welfare. State.

\title{
1. Introdução
}

O presente artigo elucida a atual necessidade de se pensar nas Políticas Públicas e como a sociedade as entende. É necessário elencar a importância das Políticas Públicas para a sociedade, numa perspectiva de romper com uma visão assistencialista e filantrópica, objetivando minimizar as desigualdades.

A Assistência Social, antes baseada na caridade e solidariedade, passou a ser reconhecida conforme a Constituição Federal de 1988, como Política Social Pública. No entanto, é necessário expor as práticas não assistencialistas com propósito de bem conceituar as políticas públicas.

Política Pública é um conceito muito utilizado no discurso dos gestores e das lideranças da sociedade civil, mas dificilmente paramos para pensar em seu significado.

As Políticas Públicas, são caracterizadas como a ação do Estado na intervenção social mediante a formulação e implementação dos padrões de proteção social. Ou seja, ações estatais desenvolvidas por meio dos programas e serviços que proporcionam a garantia de direitos e condições dignas de vida ao cidadão de forma equilibrada e justa.

Sua caracterização foi necessária quando, em dado momento da história moderna, as pessoas perceberam que a burocracia estatal não deveria apenas garantir a ordem e a segurança social, mas também prover serviços destinados a diminuir as desigualdades sociais e promover o crescimento econômico.

Portanto, política pública compreende o conjunto de intervenções e ações do Estado orientadas para a geração de impactos nas relações sociais, sendo que as mais conhecidas são 
as políticas de educação, saúde, assistência social, transporte e habitação, entre outros. Apesar de surgir como uma concepção universalista, por exemplo, com o passar do tempo vai ganhando uma conotação mais focalizada, destinada aos mais "desfavorecidos", como políticas compensatórias promovidas pelo Estado para minimizar a "questão social” a forma como as elites político econômicas chamavam as epidemias, os enormes contingentes de desempregados, a violência urbana e as manifestações populares contra a pobreza e a exploração industrial.

Mas somente no século XX, em especial na Europa Ocidental após a Segunda Guerra Mundial, é que surge a ideia de política pública como um direito que todo cidadão possui, independente da sua condição social. Para isso, é preciso definir dois aspectos básicos: como construí-las e como financiá-las?

Ainda hoje se faz necessário averiguar, distinguir e avaliar se trata de assistencialismo meramente eleitoreiro e/ou partidário, ou se realmente se trata de políticas públicas com objetivos sérios e que visem o desenvolvimento econômico e social.

\section{A relação entre assistência social e políticas públicas}

\subsection{Origens e Propósitos}

As Políticas Públicas no Brasil começaram a surgir como alternativa para apaziguar os conflitos que existiam entre as classes sociais, conflitos estes decorrentes do processo de consolidação do sistema capitalista, a fim de harmonizar essas relações, e não com o intuito de gerar o bem estar social. A implantação das políticas públicas no Brasil se deu em um processo lento, estas foram construídas por meio de muita luta e reivindicações da classe trabalhadora.

E hoje, um dos principais temas de estudo tem sido investigar a forma de avaliação destas políticas públicas e programas lançados pelo governo no intuito de melhorar as condições de vida dos brasileiros, essa avaliação tem se processado através de dois tipos de análise, a primeira se constitui numa análise da evolução do gasto público e a segunda fundamenta-se em uma análise econômica que tem como objetivo identificar o grau com que os recursos governamentais são utilizados para a produção de bens e serviços.

Desta forma, o surgimento das Políticas Públicas no Brasil está relacionado com ascensão do sistema capitalista culminando na Revolução Industrial, como também das lutas de classes e do movimento da intervenção do Estado nas relações sociais e econômicas. 
Já a Política Pública enquanto área de conhecimento e disciplina acadêmica nasce nos Estados Unidos da América (EUA), rompendo ou pulando as etapas seguidas pela tradição europeia de estudos e pesquisas nessa área, que se concentravam mais na análise sobre o Estado e suas instituições do que propriamente na produção dos governos. Assim, na Europa, a área de Política Pública surge como um desdobramento dos trabalhos baseados em teorias explicativas sobre o Estado e sobre o papel de uma das mais importantes instituições do Estado, ou seja, o governo produtor de Políticas Públicas.

$\mathrm{Na}$ área do governo propriamente dito, a introdução da Política Pública como ferramenta das decisões do governo é produto da Guerra Fria e da valorização da tecnocracia como forma de enfrentar suas consequências. A proposta de aplicação de métodos científicos às formulações e decisões do governo sobre problemas públicos se expande depois para outras áreas da produção pública, inclusive para a área social, a área ainda contou com quatro grandes "pais" fundadores: H. Laswell, H. Simon, C. Lindblom e D. Easton.

Em seu contexto histórico a assistência social surge por ações que objetivam dar uma organização às formas de assistencialismo. A esta condição, temos as relações de dominação de classe, através da articulação da burguesia com a igreja. Neste sistema de organização social capitalista, a burguesia se aliava com a Igreja e o Estado para profissionalizar a assistência social. O Estado pretendia implementar medidas legislativas através de uma assistência social populista e também assistencialista.

A assistência social como política social se caracteriza por sua intervenção social, como também pela relação mútua com os interesses econômicos da classe dominante, demonstrando sua incapacidade de interferir na realidade da questão social brasileira. De acordo com Couto:

\footnotetext{
No caso da assistência social é ainda mais grave. Apoiada por décadas na ideia de favor, do clientelismo, do apadrinhamento e do mando, que configurou um padrão arcaico de relações, enraizado na cultura política brasileira, esta área de intervenção do Estado caracterizou-se historicamente como não política, renegada como secundaria e marginal do conjunto das políticas públicas (COUTO, 2014, p.33).
}

A história da assistência social, concebida como política pública é bastante nova em nossa sociedade. Para compreendermos melhor é necessário remetermos ao passado histórico. Tradicionalmente, as necessidades de proteção social eram supridas pelos chamados agentes de sociabilidade primária, sendo eles, igreja, família, grupos e associações. 


\begin{abstract}
"Essa concepção de necessidades de proteção social, temos como exemplo algumas passagens da Bíblia, que historicamente, influenciou tanto as ações da Igreja como a consolidação de uma restrita visão assistencialista e compensatória que, efetivamente, até hoje, incide sobre as práticas de "combate" às desigualdades sociais e o processo de estruturação de um conjunto de ações direcionadas aos caracterizados como mais visivelmente "vulnerabilizados" pela miséria (RIBEIRO, 2007, p.2).
\end{abstract}

No Brasil, as políticas sociais passam a ter uma visibilidade a partir da década de 1980, a qual foi marcada por pontos cruciais, entre os quais o momento efervescente dos movimentos sociais na luta pela democracia e pelos direitos sociais. Em síntese, dessas lutas obteve-se a Constituição Federal de 1988, considerada a "Constituição Cidadã”, que registra o grande avanço em relação aos direitos sociais e a assistência social. A Constituição Federal foi uma grande conquista para o cidadão e a sociedade como todo. Para Simões (2010, p. 294) "A Constituição Federal concebe a assistência social como política de seguridade social de responsabilidade do Estado e direito do cidadão (arts. 203 e $204 \mathrm{CF}$ )".

Esta constituição foi a porta de entrada para o início da construção da política de assistência social na condição de política pública, dever do Estado e direito da população. Passando a trabalhar os mínimos sociais e combatendo os agravamentos da questão social por meio dos seus programas e serviços socioassistenciais.

\begin{abstract}
Segundo a Lei, a assistência tem por finalidade assegurar a prestação das necessidades básicas, com base nas quais as políticas públicas, com a participação da comunidade, definem os mínimos sociais, de natureza mais ampla. Para reduzir os níveis de pobreza, prevê diversas estratégias: criação de programas de geração de trabalho e renda; proteção a maternidade, as crianças e aos adolescentes; apoio a gestantes; pessoas com deficiência ou pessoas idosas, desde que carentes por meio de ações continuadas de assistência social (SIMÕES, 2010, p. 295).
\end{abstract}

A assistência social sempre se apresentou aos segmentos progressistas da sociedade como uma prática e não como uma política, era vista até como necessária, mas vazia de consequências transformadoras, sua execução tinha caráter sempre de provisoriedade, mantendo-se isolada e desarticulada de outras práticas sociais.

A assistência social ao longo de seu processo histórico transitou do assistencialismo clientelista para o campo da política social, esta como política de Estado passa a ser um campo de defesa e atenção dos interesses dos segmentos mais empobrecidos da sociedade (YAZBEK, 1995, p.10).

As políticas sociais governamentais são entendidas como um movimento multidirecional resultante do confronto de interesses contraditórios e também enquanto mecanismos de enfrentamento da questão social, de distribuição das demais políticas e 
resultantes do agravamento da crise sócio econômica, das desigualdades sociais, da concentração de renda e do empobrecimento da população.

Isso era visto de forma separada, com caráter residual, próxima das práticas filantrópicas e de privilégios e não como mecanismos possíveis de universalização de direitos sociais.

Em 1993 a Lei no 8.742 dispõe sobre a organização da assistência social, constituindose na Lei Orgânica da Assistência Social (LOAS), que assegura a assistência social como direito do cidadão e dever do Estado e como Política de Seguridade Social não contributiva, assegura também a participação de organizações públicas e privadas na realização de ações de assistência social para o atendimento das necessidades básicas sociais.

A LOAS sistematizou e institucionalizou como permanentes, os serviços assistenciais as famílias em situação de vulnerabilidade e risco social. Representou a maioridade jurídica da assistência social, na historia brasileira, instituindo em seu estatuto como política pública de Estado, integrada a seguridade social (SIMÕES, 2010, p. 295).

\subsection{O que de fato são Políticas Públicas?}

A definição mais conhecida continua sendo a de Laswell, ou seja, decisões e análises sobre Política Pública implicam em responder às seguintes questões: quem ganha o quê, por que e que diferença faz, enfatizando o papel da Política Pública na solução de problemas.

No entanto, definições de Políticas Públicas, mesmo as minimalistas, guiam o nosso olhar para a questão dos embates em torno de interesses, preferências e ideias se desenvolvem, isto é, os governos. Apesar de optar por abordagens diferentes, as definições de Políticas Públicas assumem, em geral, uma visão global do tema, uma perspectiva de que o todo é mais importante do que a soma das partes e que indivíduos, instituições, interações, ideologia e interesses contam, mesmo que existam diferenças sobre a importância relativa desses fatores.

É inegável que o termo "Políticas Públicas" está presente em inúmeras áreas do conhecimento, embora seja notório que é no âmbito da Ciência Política que ele ganha maior destaque, principalmente a partir da metade do século XX. O conhecimento produzido na área de Políticas Públicas vem servindo à políticos, empresas comprometidas socialmente e por todos aqueles que veem as mesmas como um caminho para a mudança e para a construção de um mundo melhor. Compreendê-las permite refletir a respeito do que vem sendo feito, o que 
está dando certo e o que poderá ser feito na perspectiva de garantir a sua efetividade, o quanto que elas estão contribuindo para melhorar a vida das pessoas.

Uma das questões mais polêmicas e divergentes no campo da Ciência Política reside justamente na definição das Políticas Públicas. São muitas as diferenças presentes na literatura especializada, uma delas se refere ao pensamento de Teixeira:

\begin{abstract}
“Políticas Públicas" são diretrizes, princípios norteadores de ação do poder público; regras e procedimentos para as relações entre poder público e sociedade, mediações entre atores da sociedade e do Estado. São, nesse caso, políticas explicitadas, sistematizadas ou formuladas em documentos (leis, programas, linhas de financiamentos) que orientam ações que normalmente envolvem aplicações de recursos públicos (TEIXEIRA, 2002, p.02).
\end{abstract}

O principal nó conceitual se dá na compreensão das mesmas enquanto exclusividade de atores estatais ou não. Alguns autores defendem a abordagem estatista, enquanto outros a chamada abordagem multicêntrica ao prever a não exclusividade do Estado em relação ao estabelecimento e implantação de Políticas Públicas.

A abordagem estatista parte da premissa de que é Política Pública somente quando provinda de ator estatal, enquanto a segunda entende o adjetivo "pública" a política voltada à um problema público e não à sua origem. Este enfoque parece o mais pertinente por vários motivos, sendo o mais significativo o fato de que o enfrentamento de um problema público pode se dar por inúmeros agentes, mesmo levando em conta o papel chave do Estado já que a elaboração de Políticas Públicas é uma das principais razões de sua existência.

Esta linha de raciocínio se demonstra interessante a partir das indagações feitas por Secchi:

\begin{abstract}
A Petrobrás tem $60 \%$ das ações em mãos privadas, então não elabora políticas públicas? Quem nomeia o presidente da Petrobrás é o presidente da República, então suas políticas são públicas? Uma organização que tenha $50 \%$ de suas ações controladas pelo Estado passaria a elaborar políticas públicas se o Estado comprasse mais uma ação? Consideramos este tipo de verificação infrutífera (SECCHI, 2010, p. 03).
\end{abstract}

Perguntas dessa natureza ajudam e facilitam tal entendimento. $\mathrm{O}$ que caracteriza a essência de uma Política Pública é o problema público, sua intencionalidade de resolver tal problema, e não de ser o tomador de decisão ou implementador seja estatal ou não estatal, ou seja, à sua natureza jurídica.

A partir do que foi colocado até então é evidente que falar de Políticas Públicas é falar de problemas coletivamente relevantes, problemas estes que podem ser definidos como a 
diferença entre a situação atual e uma situação ideal possível. Nesse sentido um problema existe quando a situação atual é considerada inadequada e quando existe a expectativa de melhorar esta situação em questão, vale a ressalva que esta avaliação é bastante subjetiva.

Pode-se então resumir, que Política Pública como o campo do conhecimento busca, ao mesmo tempo, colocar o governo em ação e/ou analisar essa ação e quando necessário, propor mudanças no rumo ou curso dessas ações. Em outras palavras, o processo de formulação de Política Pública é aquele através do qual os governos traduzem seus propósitos em programas e ações, que produzirão resultados ou as mudanças desejadas no mundo real.

\section{Avaliação das políticas públicas}

No final do século XX, com as discussões em torno da crise do welfare state (o estado do bem-estar), com as revoltas econômicas, sociais e políticas enfrentadas, principalmente a partir do final da década de 1970, junto com o movimento da nova administração pública, o Estado é intensamente questionado e pressionado tanto em suas funções quanto na eficácia de suas ações interventoras no meio social. Compreendendo que o sucesso e do fracasso das Políticas Públicas é fundamental para o melhor desempenho da administração pública, desta forma deve-se ser avaliado.

Avaliar significa determinar o valor de algo. Porém, sabemos que não existe um consenso quanto ao que seja avaliação de políticas públicas, pois o conceito admite várias definições, algumas delas bem contraditórias. Esse fato se explica justamente porque a área de políticas públicas é desmembrada para uma variedade de disciplinas, instituições e executores, abrangendo diversas questões, necessidades e pessoas.

Ala-Harja e Helgason, (2000, p. 8) definem avaliação em termos simples, afirmando que "o termo compreende a avaliação dos resultados de um programa em relação aos objetivos propostos".

Já Garcia a define como:

Avaliação é uma operação na qual é julgado o valor de uma iniciativa organizacional, a partir de um quadro referencial ou padrão comparativo previamente definido. Pode ser considerada, também, como a operação de constatar a presença ou a quantidade de um valor desejado nos resultados de uma ação empreendida para obtê-lo, tendo como base um quadro referencial ou critérios de aceitabilidade pretendidos (GARCIA, 2001, p. 31). 
O real objetivo de uma avaliação é determinar a viabilidade, pertinência e alcance e eficiência de seus objetivos, bem como efetividade, impacto e sustentabilidade de seu desenvolvimento. A avaliação deve proporcionar informações que sejam razoáveis e úteis para permitir a tomada de decisões. A avaliação deve ser vista como um mecanismo de progresso e segurança no processo de tomada de decisões, a fim de garantir melhores informações, sobre as quais eles possam fundamentar e respaldar tais decisões e melhor prestar contas sobre a aplicação das políticas públicas.

\subsection{Métodos de avaliação das políticas públicas}

As avaliações das Políticas Públicas podem ser classificadas como intermediárias, também podem ser chamadas de formativas e são conduzidas durante a implementação de um programa como meio de se adquirir mais conhecimento quanto a um processo para o qual se deseja contribuir. $\mathrm{O}$ objetivo aqui é dar suporte e melhorar a gestão, a implementação e o desenvolvimento do programa.

Já as avaliações posteriores à implementação do programa são chamadas ex post ou somativas, pois visam trabalhar com impactos e processos, portanto, estuda-se a eficácia e o julgamento do valor geral do programa, dando mais objetividade e credibilidade aos achados.

O que de fato devemos primar é a neutralidade da avaliação. Pois se torna muito difícil que avaliações realizadas pelas próprias equipes governamentais encarregadas da execução de uma dada política sejam razoavelmente isentas, ainda que saibamos que uma neutralidade absoluta seja impossível.

O ideal seria que as avaliações pudessem ser discutidas no campo público, onde os cidadãos pudessem ter pleno acesso às informações, à metodologia empregada e aos resultados alcançados, para que assim pudessem se tornar um verdadeiro instrumento democrático de controle e auxílio à ação dos governantes.

Quando se busca uma postura mais abrangente sobre a metodologia de avaliação de políticas devemos pensar que a avaliação é uma forma de mensuração, de julgamento de valor, então antes de tudo é preciso estabelecer os critérios de avaliação e nesse ponto não há uma conformidade sobre aspectos metodológicos e conceituais.

A aplicação de critérios vai depender de uma operacionalização para identificação e quantificação dos resultados então obtidos. A operacionalização poderá ser feita, por meio de indicadores, ou seja, um parâmetro, ou valor derivado de parâmetros que forneçam informações sobre o estado de um fenômeno, com uma extensão significativa. 
Tem-se em mente os critérios e indicadores a serem utilizados, conforme Garcia são eles:

- absolutos (as metas estabelecidas são consideradas como o padrão a ser alcançado);

- $\quad$ históricos (comparação dos resultados ao longo do tempo);

- normativos (comparação do desempenho com programas similares ou semelhantes);

- $\quad$ teóricos (estabelecidos na própria elaboração do programa, sob a hipótese da obtenção dos resultados planejados);

- negociados ou de compromisso (baseiam-se em algum procedimento específico para sua fixação, normalmente decorrente de consensos entre as partes envolvidas na gestão e os formuladores. (GARCIA, 2001, p. 7-70).

Assim, podemos desenhar um programa público sintetizado em uma sequência que corresponde a uma agregação de objetivos conforme a tradição brasileira hierarquizada. Segundo Costa e Castanhar (2003, p. 962-969), a sequência de compromissos de um programa público deve ser organizado da seguinte forma: propósito - objetivo - meta atividade.

\section{Perspectivas e desafios para as políticas públicas de assistência social}

Neste momento o que se espera é um novo posicionamento do estado, de forma que seja possível discutir, eticamente, o que precisamos fazer no campo dos direitos sociais e da cidadania, deixando de lado a tese de que a Lei Orgânica da Assistência Social é uma lei dos pobres ou que propõem um conjunto de benefícios que somente envolve a organização do Estado e das medidas administrativas, até porque a pobreza e a miséria não se resolvem com um conjunto de benefícios.

A situação da pobreza somente poderá ser alterada quando houver vontade política efetiva do governo e da sociedade no sentido de um melhor trabalho, salário digno, condições de vida de distribuição da renda no mínimo razoável, construindo assim a defesa dos mínimos sociais necessários à vida digna de cada cidadão brasileiro.

Segundo a LOAS a política de assistência social para ganhar níveis de efetividade desejáveis e urgentes, precisa ser descentralizada, desmembrada.

Esse desmembramento consiste em uma efetiva partilha de poder entre o governo e as coletividades locais, implicando a autogestão local e está profundamente atrelada a reforma do Estado, em novas formas de relação do povo e seu governo, dentro do qual a autonomia 
das organizações locais proporcione o exercício de controle das coletividades locais, objetivando assim um avanço democrático.

Uma municipalização faria este papel, uma vez que pudesse ser entendida como processo que levasse os serviços mais próximos a população e não apenas repassasse encargos para as prefeituras, seria a passagem de serviços e encargos a serem desenvolvidos mais satisfatoriamente pelos municípios, com uma adequada distribuição de poderes políticos e financeiros.

O desmembramento e a municipalização, como consolidação democrática, estão sempre ligados à participação e mostram que a força da cidadania está no município, pois é no município que o cidadão nasce, cresce, vive e constrói sua história, desta forma tem a responsabilidade de fiscalizar e exercitar o controle social.

Porém, ainda se faz necessário enfatizar a importância da participação legítima e real da sociedade civil e do governo na discussão da Política Pública de assistência social. Participação legítima entende-se aquela que dá origem a algo novo e a participação real precisa ser feita envolvendo todos os atores sociais e retirando de cena o Estado como poder central, é a hora de dividir o palco com a sociedade civil e os governos municipais.

Entretanto, neste processo temos de pensar na Política Pública e na assistência social sob a lógica do direito, conhecer suas possibilidades e limites, pois o fortalecimento do poder local representa, sem dúvida, uma real contribuição para a retomada da democracia e da cidadania em nosso país neste momento.

\section{Conclusões}

Nesse contexto, o que podemos perceber ainda são as deficiências desses modelos de Políticas Públicas e de suas avaliações. A sociedade brasileira ainda vive este tipo de "falha" no que tange as políticas de um governo populista, até mesmo nos governos de esquerda. $\mathrm{O}$ País passou e continua passando por situações de conciliação entre os líderes de governo e os grandes empresários.

De fato, em algumas medidas com relação à competência de algumas atividades em termos de terceirização e privatização podemos sim afirmar a existência de melhoras, todavia qualquer oscilação deixa evidente que a sociedade ainda depende desses agentes econômicos que determinam os papéis na economia da sociedade, quando tal atitude deveria ser de total competência e influência do Estado. Ainda que não se tenham receitas prontas como afirma Rodrigues: 
(...) ao encarar os problemas dos outros como de todos nós, visto que são problemas públicos, abrimos uma janela de oportunidade para que as políticas públicas que produzimos façam, de fato, diferença para a sociedade em que todos vivemos (RODRIGUES, 2010, p. 10).

Um olhar mais apurado sobre os projetos de enfrentamento à pobreza colaboraria em muito para que, ao serem formulados dentro de novos métodos e respectivos conteúdos pudessem ser reorientadas para as estratégias de desalienação e de emancipação dos grupos populacionais socialmente vulnerabilizados, em uma dinâmica política e técnica, produtora de espaços de reconhecimento individual, de resgate da autoestima e de integração comunitária e coletiva, com serviços e programas básicos de orientação e de reflexão sobre temas centrais dos processos de fortalecimento de uma cultura cidadã, com ênfase nas experiências de solidariedade, de construção de valores e de lutas comuns, objetivando uma real alteração nas condições de vida.

Ressalta-se também a necessidade de fortalecimento da articulação da assistência social com as demais políticas sócio econômicas setoriais, no sentido de tornar eficiente a feição universal dessas Políticas Públicas, principalmente a saúde e a educação, com o objetivo central de se trabalhar com a perspectiva de superação da exclusão social.

Conclui-se, portanto, que é de extrema importância que a sociedade deixe de ser apática, mal informada e manipulável, é necessário que esta sociedade busque conhecimento da verdadeira importância do significado da palavra cidadão, de modo que seu conceito saia do papel e se legitime através da incorporação da identidade de um indivíduo marcado por suas vitórias, como sujeito construtor e autor de uma cidadania democrática, para que seja capaz de, ainda que a longo prazo, conhecer e perceber os seus direitos e assim consiga de fato reivindicá-los.

\section{Referências}

ALA-HARJA, Marjukka; HELGASON, Sigurdur. Em direção às melhores práticas de avaliação. Revista do Serviço Público, Brasília, v. 51, n. 4, p. 5-59, out./dez. 2000.

ARRETCHE, Marta. Dossiê agenda de pesquisa em políticas públicas. Revista Brasileira de Ciências Sociais, São Paulo, v. 18, n. 51, p. 7-9, fev. 2003.

BRASIL. CONSTITUIÇÃO DA REPÚBLICA DOS ESTADOS UNIDOS DO BRASIL (DE 24 DE FEVEREIRO DE 1891) disponível em http://www.planalto.gov.br. 
COSTA, Frederico Lustosa da; CASTANHAR, José Cezar. Avaliação de programas públicos: desafios conceituais e metodológicos. Revista de Administração Pública, Rio de Janeiro, v. 37, n. 5, p. 962-969, set./out. 2003.

COUTO, Berenice Rojas et al. O Sistema Único de Assistência Social no Brasil: uma realidade em movimento. Cortez Editora, 2014, p. 33.

GARCIA, Ronaldo Coutinho. Subsídios para organizar avaliações da ação governamental. Planejamento e Políticas Públicas, Brasília, n. 23, p. 7-70, jan./jun. 2001.

LIMA, Waner Gonçalves. Política pública: discussão de conceitos. Revista Interface (Porto Nacional), [S.1.], n. 05, nov. 2012. ISSN 2448-2064. Disponível em: https://sistemas.uft.edu.br/periodicos. Acesso em: 06 ago 2017.

Revista Brasileira de Ciências Sociais, São Paulo, v. 18, n. 51, p. 15-20, fev. 2003.

RODRIGUES, M. M. A. Políticas públicas. São Paulo: Publifolha, 2010.

SECCHI, Leonardo. Introdução: percebendo as políticas públicas. Políticas Públicas: conceito, esquemas de análise, casos práticos. São Paulo: Cengage Learning, 2010.

SIMÕES, Carlos. Curso de direito do serviço social. 4. ed. São Paulo: Cortez, 2010

SOUZA, Celina. "Estado do campo" da pesquisa em políticas públicas no Brasil, 2003.

TEIXEIRA, Elenaldo Celso. O Papel das Políticas Públicas no Desenvolvimento Local e na Transformação da Realidade. AATR-BA, 2002.

YAZBEK, Maria Carmelita. Os fundamentos históricos e teórico-metodológicos do Serviço Social brasileiro na contemporaneidade. CFESS, ABEPSS. Serviço Social: direitos sociais e competências profissionais. Brasília-DF. 2009 